\title{
A Prediction Method for Postconstruction Settlement of Pile-Soil Composite Subgrade Based on Fuzzy Comprehensive Evaluation
}

\author{
Hao Shan $\mathbb{D}^{1},{ }^{1}$ Guanghui Jiang, ${ }^{2}$ Yajing Chang, ${ }^{2}$ Junli Cheng, ${ }^{2}$ Baoning Hong, \\ and Shengcheng Wang ${ }^{1}$ \\ ${ }^{1}$ School of Civil Engineering, Xuzhou University of Technology, Xuzhou 221018, China \\ ${ }^{2}$ CSCEC Road and Bridge Group CO.,LTD, Shijiazhuang 050001, China \\ ${ }^{3}$ Key Laboratory of Ministry of Education for Geomechanics and Embankment Engineering, Hohai University, \\ Nanjing 210098, China \\ Correspondence should be addressed to Hao Shan; shanhao@xzit.edu.cn
}

Received 10 September 2020; Revised 8 August 2021; Accepted 28 August 2021; Published 14 September 2021

Academic Editor: Hailing Kong

Copyright (c) 2021 Hao Shan et al. This is an open access article distributed under the Creative Commons Attribution License, which permits unrestricted use, distribution, and reproduction in any medium, provided the original work is properly cited.

\begin{abstract}
This paper presents a postconstruction settlement prediction method for pile-soil composite subgrade based on the multilevel fuzzy comprehensive evaluation principle. In this method, the variation range of postconstruction settlement can be obtained from a simple calculation based on the basic data of actual engineering. Firstly, according to the characteristics of influencing factors in the construction of soft soil subgrade, the evaluation index set and two-level factor index sets were selected. The grading standards of the evaluation index and factor index were determined according to the allowable value of the standard and the numerical simulation results. Secondly, each factor index was standardized, and the normal distribution function in the form of exponential was used to construct the standard membership function for the first and second factor indexes. Finally, the comprehensive evaluation matrix of postconstruction settlement of composite subgrade was constructed based on the entropy weight method. The variation range of postconstruction settlement was predicted by the principle of maximum membership. The example analysis shows that the predicted results of the prediction method and the field measurement method are in good agreement, indicating that the proposed method can realize the postconstruction settlement prediction of composite subgrade, and the results are more accurate and more instructive.
\end{abstract}

\section{Introduction}

The postconstruction settlement of the composite subgrade of expressways has always been concerned by both academia and industry, especially in some special sections, such as bridge head transition sections and the sections containing structures $[1,2]$. Higher requirements are put forward for the postconstruction settlement of subgrade in these sections. So people often adopt the foundation treatment method of pile-soil composite subgrade. Compared with other foundation treatment methods, pile-soil composite subgrade has certain advantages in improving the stability of subgrade and reducing settlement. However, there are still some large postconstruction settlements in the treatment section of pile-soil composite subgrade, such as car jump at the bridge head. Many scholars and engineers have carried out much useful work in the prediction of postconstruction settlements by means of theoretical analysis [3], numerical simulation [4], and on-site observation data fitting $[5,6]$. Previous related works on postconstruction settlement prediction are discussed and tabulated in Table 1.

In this paper, based on a large amount of postconstruction settlement field test data, a new prediction method of postconstruction settlement of composite subgrade is proposed using the multilevel fuzzy comprehensive evaluation method. This method calculates the variation interval of postconstruction settlement through a simple calculation by only considering the basic data from actual projects. The calculation results are beneficial to the optimization of design and improvement of construction 
TABLE 1: Previous related works on foundation settlement.

\begin{tabular}{|c|c|c|c|}
\hline Authors & Data set size & Method & Reliable condition \\
\hline Omar et al. [7] & $\begin{array}{l}\text { Footing width, effective unit weight, and } \\
\text { SPT blow count }\end{array}$ & Artificial neural network & $\begin{array}{c}\text { Shallow foundation on granular } \\
\text { soils }\end{array}$ \\
\hline Wang et al. [8] & $\begin{array}{l}\text { Soil properties and parameters related to } \\
\text { the pile, such as pile spacing, pile length, } \\
\text { and cap width }\end{array}$ & $\begin{array}{l}\text { A calculation model for predicting the } \\
\text { additional stresses in the composite } \\
\text { foundation soil and the layerwise } \\
\text { summation method }\end{array}$ & $\begin{array}{l}\text { Composite foundation with } \\
\text { sparse prestressed tubular } \\
\text { concrete (PTC) capped-piles } \\
\text { under embankment }\end{array}$ \\
\hline Meng et al. [9] & $\begin{array}{c}\text { The compression parameters of } \\
\text { underlying soils related to soil } \\
\text { disturbance degree }\end{array}$ & The layerwise summation method & Ground and tunnel \\
\hline Eid et al. [3] & $\begin{array}{l}\text { Pile-subgrade stiffness ratios for piled } \\
\text { foundations on nonhomogeneous media }\end{array}$ & $\begin{array}{l}\text { Three-dimensional finite-element (FE) } \\
\text { analysis }\end{array}$ & $\begin{array}{l}\text { The elastic settlement of piled } \\
\text { foundations resting on rock }\end{array}$ \\
\hline Hong et al. [2] & $\begin{array}{l}\text { The time-extended loading residual } \\
\text { settlement and settlement rate calculated } \\
\text { from the field test data }\end{array}$ & $\begin{array}{l}\text { An improved static loading test method, } \\
\text { time-extended loading test }\end{array}$ & Pile-soil composite subgrade \\
\hline Kermani et al. [10] & Rockfill modulus and rock strength & $\begin{array}{c}\text { A novel approach considering the dam's } \\
\text { deformation behavior during } \\
\text { construction }\end{array}$ & Concrete face rockfill dams \\
\hline Wang et al. [5] & $\begin{array}{l}\text { Three appropriate points for the } \\
\text { measured settlement curve in the } \\
\text { prediction samples }\end{array}$ & $\begin{array}{l}\text { A three-point hyperbolic combination } \\
\text { model }\end{array}$ & $\begin{array}{l}\text { Subgrade filled with construction } \\
\text { and demolition waste }\end{array}$ \\
\hline Cai et al. [11] & The calculated dynamic stresses & $\begin{array}{l}\text { The equivalent timeline model } \\
\text { combined with the cyclic strain } \\
\text { accumulation model }\end{array}$ & $\begin{array}{l}\text { The long-term settlements of } \\
\text { roads on soft soil under cyclic } \\
\text { traffic loadings }\end{array}$ \\
\hline $\begin{array}{l}\text { Mohammed et al. } \\
{[12]}\end{array}$ & $\begin{array}{l}\text { The width of footing, pressure of footing, } \\
\text { geometry of footing, count of SPT blow, } \\
\text { and ratio of footing embedment }\end{array}$ & Machine learning models & $\begin{array}{l}\text { Settlement of shallow foundation } \\
\text { over cohesion soil properties }\end{array}$ \\
\hline Tang et al. [13] & $\begin{array}{c}\text { The observation data of settlement } \\
\text { during construction }\end{array}$ & $\begin{array}{l}\text { The Hushino model, hyperbolic curve } \\
\text { method, and exponential curve method }\end{array}$ & Foundation after construction \\
\hline $\begin{array}{l}\text { Ding [14] and } \\
\text { Zhang et al. [15] }\end{array}$ & The design parameters & Numerical simulation approach & Pile-soil composite subgrade \\
\hline
\end{tabular}

quality. In the establishment process of this method, it is difficult to calculate weight and membership degree accurately, and there are many factors involved. Hence, the entropy weight method, standardized membership function, and two-level evaluation system are introduced. In this way, not only the calculation accuracy is improved but also the index of influencing factors involved in the comprehensive evaluation in each level is reduced, which is more convenient for practical applications.

\section{Need for Research}

In recent years, artificial intelligence technology has been developed rapidly, but at present, artificial intelligence technology still has some shortcomings and limitations [16-18]. Firstly, it needs more data and data support to build the model. When the data are insufficient, the error is often large. Secondly, sometimes, in the modeling process, some engineering features or states need to be represented by numbers, which will lead to the loss of information. Finally, the results obtained by the artificial intelligence technology model are usually qualitative indicators, while the quantitative indicators are relatively few and not rigorous enough. However, in addition to the aforementioned disadvantages, artificial intelligence technology also has obvious advantages [19-21]. First of all, it is an important tool for system analysis and will not cut the relationship between influencing factors and results. Secondly, it can solve complex relationships between multiple factors and predict unknown data. Finally, its analysis results are often more concise, easy-to-make decisions.

Considering that the advantages of artificial intelligence technology have a great help to solve complex engineering problems, some artificial intelligence technologies have been widely used in civil engineering. To predict the settlement of rock-socketed piles, Danial et al. [22, 23] presented the development of a hybrid ANN-based model named PSOANN (or neuro-swarm) with detailed modeling process and a new model based on gene expression programming (GEP). $\mathrm{Li}$ et al. [16] use least squares support vector machines (LSSVMs) based on multipoint measurement to monitor and predict foundation pit displacement. In addition, fuzzy comprehensive evaluation (FCE) method is also a typical artificial intelligence technology; it can better solve the fuzzy but difficult to quantify the problem and is suitable for all kinds of nondeterministic problems. The FCE method has been widely used in mineral [24], environmental [25], slope [26] and other engineering areas [27]. However, its application in postconstruction settlement of composite subgrade has not been reported. As the postconstruction settlement of composite subgrade involves many factors and has obvious randomness, it is meaningful to explore the method of uncertainty and establish a prediction model and a calculation method. 


\section{Evaluation Index and Influencing Factors}

As the postconstruction settlement of composite subgrade can be affected by many factors, a two-level fuzzy comprehensive evaluation system considering the main influencing factors is selected. The evaluation system can make up for the shortcomings of the existing single-level evaluation methods and make the evaluation results more accurate and more instructive [20]. In the two-level fuzzy comprehensive evaluation system, one of our key works is to determine the reasonable evaluation index set and the factor index set of each layer for improving the accuracy and practicability of the prediction method.

3.1. Evaluation Index Set. In the two-level fuzzy comprehensive evaluation system, an evaluation index $v$ is constructed for describing the severity of the postconstruction settlement of the composite subgrade, and we have

$$
V=\left\{v_{1}, v_{2}, \ldots, v_{m}\right\},
$$

where $V$ is a set that contains all the possible values of the evaluation index $v$. According to the requirements of the current specification in China, allowable values for the postconstruction settlements of high-quality highways at the bridgehead transition section, structural section, and general road section are 100,200 , and $300 \mathrm{~mm}$, respectively. Therefore, the element $v m$ in the evaluation index set $V$ is obtained based on the postconstruction settlement value. The smaller the postconstruction settlement value, the better the construction quality. In this paper, the evaluation index set contains four values to represents four quality grades (see Table 2.

The space of the postconstruction settlement has been divided into four subsections, and the corresponding normalized classification intervals (w.r.t $400 \mathrm{~mm}$ ) are also given in Table 1. For the postconstruction settlement larger than $400 \mathrm{~mm}, 400 \mathrm{~mm}$ is applied to the normalization process. Hence, we have a closed range of the postconstruction settlement after the normalization process.

3.2. Influencing Factors Set. Since the postconstruction settlement of CFG pile composite subgrade-based road section involves many influencing factors, a two-level fuzzy comprehensive evaluation model is adopted to tackle the problem: 15 secondary influencing factors are constructed as the leaves of 4 primary influencing factors (geology, pile, cushion, and construction). Mathematically, we have

$$
\begin{aligned}
U & =\left\{U_{1}, U_{2}, U_{3}, U_{4}\right\}, \\
U_{i} & =\left\{u_{i 1}, u_{i 2}, \ldots u_{i j}, \ldots, u_{i n_{i}}\right\}, \quad i=1,2,3,4 \text { and } j=1,2, \ldots, n_{i},
\end{aligned}
$$

where $U_{i}$ is the primary influencing factor, $u_{i j}$ is the secondary influencing factor, and $n_{\mathrm{i}}$ is the number of secondary influencing factors included in $U_{i}$.

The factor values of the secondary influencing factors vary with the engineering characteristics. Taking CFG pile composite subgrade in Guangdong Province as an example, this paper discusses the method of determining the secondary influencing factors. According to the collected sample data of a large number of CFG pile composite subgrade engineering projects, existing specification requirements, and on-site survey results collected by the authors, the range of the factor for each secondary influencing factor is provided as follows.

The influencing factors of the geology $U_{1}$ consist of compressed soil thickness $u_{11}$, compression modulus $u_{12}$, cohesion $u_{13}$, and internal friction angle $u_{14}$.

In practical projects, the depth of CFG piles should not exceed $30 \mathrm{~m}$. Otherwise, the quality of composite subgrade is not easy to control. Therefore, the range of compressed soil thickness $u_{11}$ should be 0 to $30 \mathrm{~m}$. The cross-board shear strength of soft soil in Guangdong region is generally 4 to $12 \mathrm{kPa}$. In the shear strength index, the minimum cohesion $c<3.2 \mathrm{kPa}$, the minimum internal friction angle $\varphi<2.1^{\circ}$, the porosity ratio is generally greater than 1.0 , and the compression coefficient is within 0.5 to $1.0 \mathrm{MPa}^{-1}$. Therefore, the range of the cohesive force $u_{13}$ is 1 to $15 \mathrm{kPa}$, the range of the internal friction angle $u_{14}$ is $1^{\circ}$ to $15^{\circ}$, and the range of compression modulus $u_{12}$ is 1 to $10 \mathrm{MPa}$.

The influencing factors of the pile $U_{2}$ consist of pile modulus $u_{21}$, pile length $u_{22}$, pile diameter $u_{23}$, and pile spacing $u_{24}$.

Generally, CFG pile length range $u_{22}$ is 0 to $30 \mathrm{~m}$, the pile diameter $u_{23}$ should be 0.35 to $0.60 \mathrm{~m}$, and the pile spacing $u_{24}$ should be 1.4 to $3.0 \mathrm{~m}$. As the CFG pile design strength range is 5 to $20 \mathrm{MPa}$, the rounding range in CFG pile compression modulus $u_{21}$ is ranging from 800 to 30,000 MPa.

The influencing factors of the cushion $U_{3}$ consist of cushion thickness $u_{31}$, cushion modulus $u_{32}$, and cushion internal friction angle $u_{33}$.

In practical projects, the general thickness of the CFG pile composite subgrade cushion is 0.3 to $0.6 \mathrm{~m}$. Considering the action of the pile top support, the thickness of the cushion $u_{31}$ is in the range of 0 to $0.8 \mathrm{~m}$. As the cushion is mainly medium coarse sand and gravel, the cushion modulus $u_{32}$ ranges from 50 to $250 \mathrm{MPa}$ and the cushion internal friction angle $u_{33}$ ranges from $15^{\circ}$ to $60^{\circ}$.

The influencing factors of the construction $U_{4}$ consist of filling height $u_{41}$, filling rate $u_{42}$, preloading height $u_{43}$, and preloading time $u_{44}$.

The filling height of expressways is mainly affected by terrain and routes. Except for a few hill areas, the filling height usually does not exceed $20 \mathrm{~m}$ (including the converted thickness of the pavement structure layer). Therefore, the filling height $u_{41}$ ranges from 1 to $20 \mathrm{~m}$. The embankment filling regular loading rate is 20 to $70 \mathrm{~mm} / \mathrm{d}$, the loading rate usually is less than $20 \mathrm{~mm} / \mathrm{d}$, and the loading rate is greater than $70 \mathrm{~mm} / \mathrm{d}$ for fast loading. For the convenience of the analysis, the filling rate $u_{42}$ ranges from 5 to $100 \mathrm{~mm} / \mathrm{d}$. Surcharge preloading mainly includes under-preloading, equal-preloading, and over-preloading. Under normal circumstances, the overloading height does not exceed $3.0 \mathrm{~m}$, and the preloading time does not exceed 1 year. Therefore, the preloading height range is 0 to $3.0 \mathrm{~m}$, and the preloading time range is 0 to 360 days. 
TABLE 2: Classification standard for postconstruction settlement.

\begin{tabular}{lccr}
\hline Evaluation index & & Postconstruction settlement $(\mathrm{mm})$ & Standard classification interval \\
\hline$v_{1}$ & Excellent & {$[0,100)$} & {$[0,0.25)$} \\
$v_{2}$ & Good & {$[100,200)$} & {$[0.25,0.50)$} \\
$v_{3}$ & Moderate & {$[200,300)$} & {$[0.50,0.75)$} \\
$v_{4}$ & Poor & {$[300,+\infty)$} & {$[0.75,1)$} \\
\hline
\end{tabular}

\section{Factor Grading Standard of Secondary Influencing Factors}

By analysing a large number of engineering samples, the finite-element numerical software can be used to calculate the single-factor influence of the representative engineering example of composite subgrade. To determine the factor grading standard of all the secondary influencing factors, the influence of the individual factor was analysed separately by taking five to six values within its range. Taking CFG pile composite subgrade as an example, Plaxis finite-element numerical software can be used to analyse the law of single-factor influence. The detailed simplified processing, calculation method, and calculation process, as well as reliability demonstration will not be discussed due to the limitation of space. The specific method to determine the grading standard of the secondary influencing factors is as follows.

4.1. Quantification of Influence of Individual Factors. According to the FEM simulation results, three categories can be concluded to describe the relationship between the postconstruction settlement changes and the secondary influencing factors.

This first category is named as positive attribute factor $u_{i j}^{+}$. As the factor $u_{i j}^{+}$increases, the postconstruction settlement value increases and the evaluation grade decreases. According to the simulation studies, compressed soil thickness $u_{11}$, pile spacing $u_{24}$, filling height $u_{41}$, and filling rate $u_{42}$ belong to this category.

The second category is named as negative attribute factor $u_{i j}^{-}$. As the factor value increases, the postconstruction settlement value decreases and the evaluation grade increases. Compression modulus $u_{12}$, cohesion $u_{13}$, pile modulus $u_{21}$, pile length $u_{22}$, pile diameter $u_{23}$, cushion thickness $u_{31}$, cushion modulus $u_{32}$, internal friction angle of cushion $u_{33}$, preloading height $u_{32}$, and preloading time $u_{33}$ belong to this category.

The third category is named as zero attribute factor. As the factor value increases, the postconstruction settlement value does not change or changes little. The internal friction angle of subgrade soil $u_{14}$ belongs to this category.

For analysing the physical quantities with different units, a normalization process is implemented to both positive and negative attribute factors (zero-attribute factor is considered as the positive attribute factor in this paper). The normalization formulas for both positive and negative attribute factors are as follows:

$$
\begin{gathered}
q_{i j}=\frac{\max \left(u_{i j}^{+}\right)-u_{i j}^{+}}{\max \left(u_{i j}^{+}\right)-\min \left(u_{i j}^{+}\right)} . \\
q_{i j}=\frac{u_{i j}^{-}-\min \left(u_{i j}^{-}\right)}{\max \left(u_{i j}^{-}\right)-\min \left(u_{i j}^{-}\right)} .
\end{gathered}
$$

According to formula (3), the normalized positive attribute factors have a negative correlation with the postconstruction settlement and a positive correlation with the evaluation grade.

The relationships between the postconstruction settlements and the normalized values of the influencing factors are concluded and shown in Figures 1 to 4 .

According to Figures 1 to 4 , the contribution of each secondary influencing factor can be obtained, which can be used as the reference for weight distribution in the fuzzy comprehensive evaluation process.

Based on Figure 1, the postconstruction settlement is very sensitive to the compressed soil thickness $q_{11}$ and the compression modulus $q_{12}$. Compared with $q_{11}$ and $q_{12}$, the changes of the cohesion $q_{13}$ have a small effect on the postconstruction settlement. The changes of the internal friction angle of subgrade soil do not influence the postconstruction settlement.

Among the influencing factors of the pile, the postconstruction settlement is sensitive to the pile modulus $q_{21}$ and pile length $q_{22}$. The pile diameter $q_{23}$ has the smallest influence on the postconstruction settlement in Figure 2.

In Figure 3, the changes of the internal friction angle $q_{33}$ and the thickness of the cushion $q_{31}$ have major effects on the postconstruction settlement. In comparison, the influence of the cushion modulus $q_{32}$ is relatively small.

Among the construction-influencing factors, the preloading height $q_{43}$ and preloading time $q_{44}$ have a major effect on the postconstruction settlement, and the effects of the filling height $q_{41}$ and filling rate $q_{42}$ are relatively small.

4.2. Grading Standard. According to the simulation and analysis results shown in Figures 1 to 4, the linear interpolation method is used to determine the relationships between the normalized factors $q_{i j}$ and the postconstruction settlement and we have $q_{i j}=f_{i j}\left(S_{p}\right)$. Where $S_{p}$ is the postconstruction settlement, $f_{i j}()$ is the linear mapping from postconstruction settlement to normalized influencing factor $q_{i j}$. Based on the derived linear relationships $f_{i j}($ ), the values of the normalized factors $q_{i j}$ can be calculated when $S_{p}$ equals 100, 200, and $300 \mathrm{~mm}$. As a result, the corresponding $u_{i j}$ can be obtained, and the grading standard can be 


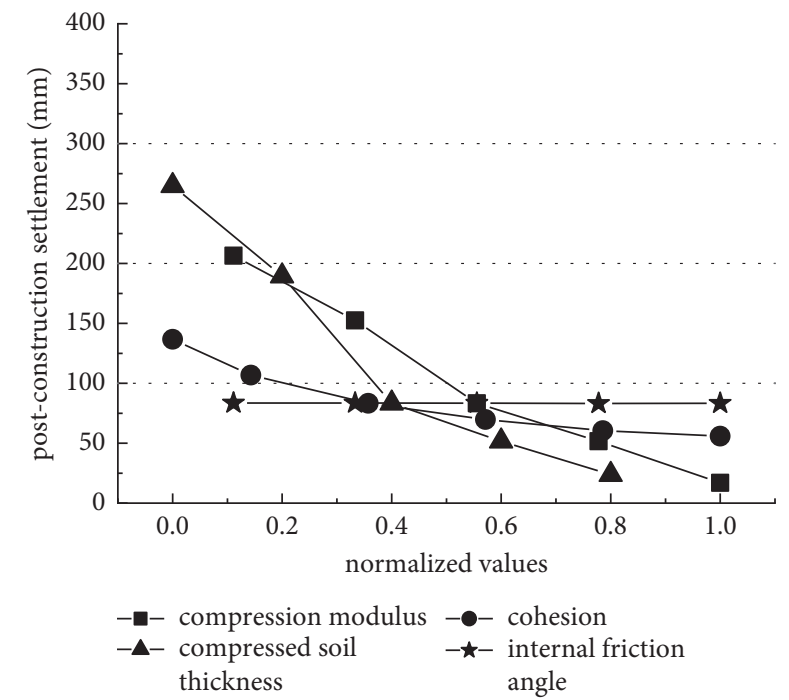

FIgURE 1: Effects of geological factors on postconstruction settlement.

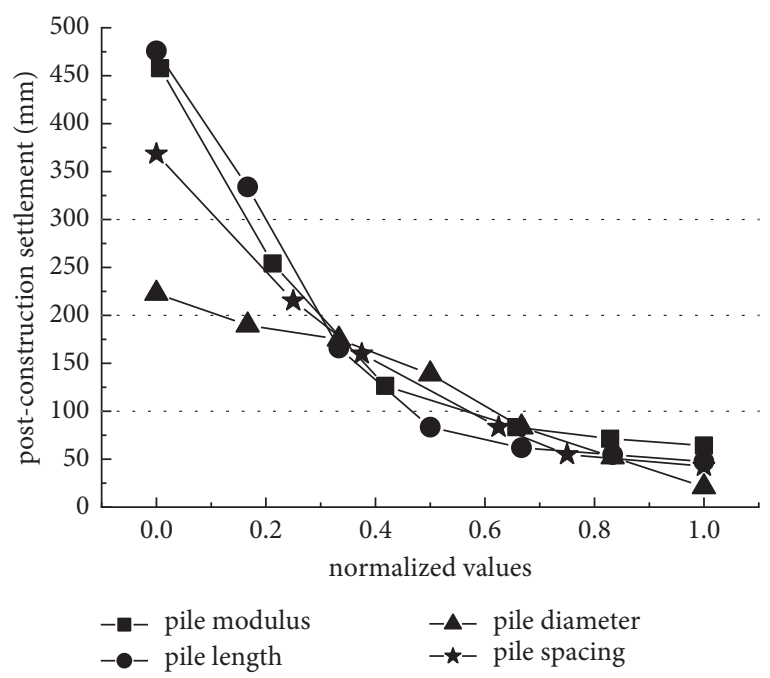

FIGURE 2: Effects of piles geological factors on postconstruction settlement.

determined. For particular influencing factors, the postconstruction settlement is smaller than $300 \mathrm{~mm}$ when $q_{i j}=0$. At the same time, we need to consider all the situations when $S_{p}>100 \mathrm{~mm}$. Hence, additional grading procedures are added as follows:

(a) $S_{p} \in[200,300)$ : the linear interpolation method is used to determine the $q_{i j}$ values when the settlement equals to 100 and $200 \mathrm{~mm}$. The $q_{i j}$ value for $S_{\mathrm{p}}=300 \mathrm{~mm}$ is equal to $0.5 f_{i j}(200)$. With the $q_{i j}$ for $S_{p}=100,200$, and $300 \mathrm{~mm}$, the corresponding $u_{i j}$ can be determined, and grading standard can be obtained.

(b) $S_{p} \in[100,200)$ : the linear interpolation method is used to determine the $q_{i j}$ value when the settlement is $100 \mathrm{~mm}$. The $q_{i j}$ value for $S_{p}=200 \mathrm{~mm}$ is equal to $0.5 f_{i j}(100)$ and the $q_{i j}$ value for $S_{p}=300 \mathrm{~mm}$ is equal

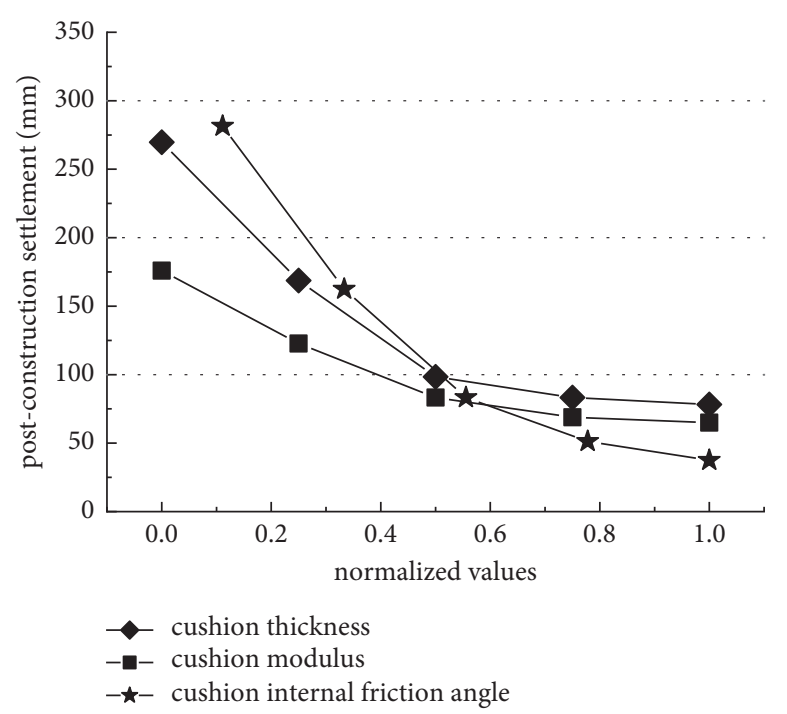

FIGURE 3: Effects of cushion factors on postconstruction settlement.

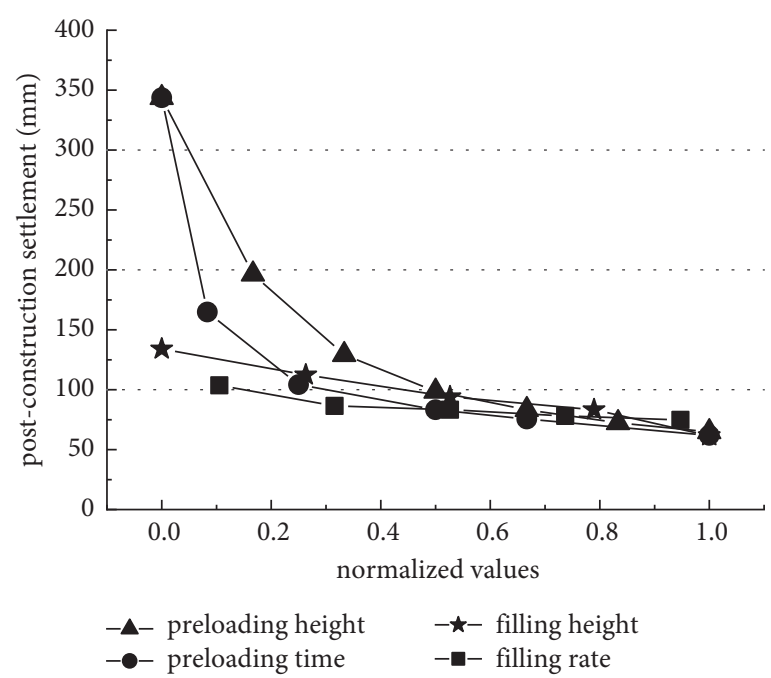

Figure 4: Effects of construction factors on postconstruction settlement.

to $0.25 f_{i j}(100)$. With $q_{i j}$ for $S_{p}=100,200$, and $300 \mathrm{~mm}$, the corresponding $u_{i j}$ can be determined, and grading standard can be obtained.

The change of friction angle in the subgrade soil does not affect the postconstruction settlement $S_{p}$. Therefore, the entire range of internal friction angle belongs to the grade $v_{1}$.

Classification standard of all the secondary influencing factors is shown in Tables 3 and 4.

\section{Membership Functions and Weights}

Based on the sensitivity analysis in the previous section and the classification standard of influencing factors in Tables 2 and 3, the membership functions and weights in the fuzzy comprehensive evaluation can be determined. As many factors are affecting the postconstruction settlement of CFG pile composite subgrade, a standardized membership 
TABLE 3: Initial conditions and classification standard of geological and pile secondary influencing factors.

\begin{tabular}{lcccccccc}
\hline \multirow{2}{*}{ Index } & \multicolumn{4}{c}{ Geological influencing factors $U_{1}$} & \multicolumn{4}{c}{ Pile influencing factors $U_{2}$} \\
& & $u_{11}(\mathrm{~m})$ & $u_{12}(\mathrm{MPa})$ & $u_{13}(\mathrm{kPa})$ & $u_{21}(\mathrm{MPa})$ & $u_{22}(\mathrm{~m})$ & $u_{23}(\mathrm{~m})$ & $u_{24}(\mathrm{~m})$ \\
\hline Initial condition & & 18 & 6 & 6 & $2 \times 104$ & 15 & 0.5 & 2.0 \\
& $v_{1}$ & $0 \sim 18.94$ & $5.52 \sim 10.00$ & $3.87 \sim 15.00$ & $17,288.90 \sim 30,000$ & $13.99 \sim 30.00$ & $0.48 \sim 0.60$ & $1.40 \sim 2.09$ \\
Classification standard & $v_{2}$ & $18.94 \sim 24.84$ & $2.24 \sim 5.52$ & $2.43 \sim 3.86$ & $9543.25 \sim 17,288.90$ & $8.99 \sim 13.99$ & $0.39 \sim 0.48$ & $2.09 \sim 2.55$ \\
& $v_{3}$ & $24.84 \sim 27.42$ & $1.62 \sim 2.24$ & $1.71 \sim 2.43$ & $5649.22 \sim 9543.25$ & $6.01 \sim 8.99$ & $0.34 \sim 0.39$ & $2.55 \sim 2.82$ \\
& $v_{4}$ & $27.42 \sim 30.00$ & $1.00 \sim 1.62$ & $1.00 \sim 1.71$ & $800.00 \sim 5649.22$ & $0 \sim 6.01$ & $0.30 \sim 0.34$ & $2.82 \sim 3.00$ \\
\hline
\end{tabular}

TABLE 4: Initial conditions and classification standard of cushion and construction secondary influencing factors.

\begin{tabular}{lcccccccc}
\hline \multirow{2}{*}{ Index } & \multicolumn{4}{c}{ Cushion influencing factors $U_{3}$} & \multicolumn{3}{c}{ Construction influencing factors $U_{4}$} \\
& & $u_{31}(\mathrm{~m})$ & $u_{32}(\mathrm{MPa})$ & $u_{33}\left({ }^{\circ}\right)$ & $u_{41}(\mathrm{~m})$ & $u_{42}(\mathrm{~mm} / \mathrm{d})$ & $u_{43}(\mathrm{~m})$ & $u_{44}(\mathrm{~d})$ \\
\hline Initial condition & & 0.6 & 150 & 40 & 6 & 50 & 2.0 & 180 \\
& $v_{1}$ & $0.40 \sim 0.80$ & $128.81 \sim 250$ & $32.89 \sim 60.00$ & $1.00 \sim 11.61$ & $5.00 \sim 85.76$ & $1.48 \sim 3.00$ & $108.30 \sim 360$ \\
Classification standard & $v_{2}$ & $0.14 \sim 0.40$ & $89.41 \sim 128.81$ & $21.85 \sim 32.89$ & $11.61 \sim 15.80$ & $85.76 \sim 92.88$ & $0.49 \sim 1.48$ & $24.10 \sim 108.30$ \\
& $v_{3}$ & $0.07 \sim 0.14$ & $69.70 \sim 89.41$ & $18.42 \sim 21.85$ & $15.80 \sim 17.90$ & $92.88 \sim 96.44$ & $0.15 \sim 0.49$ & $7.32 \sim 24.10$ \\
& $v_{4}$ & $0 \sim 0.07$ & $50.00 \sim 69.70$ & $15.00 \sim 18.42$ & $17.90 \sim 20.00$ & $96.44 \sim 100.00$ & $0 \sim 0.15$ & $0 \sim 7.32$ \\
\hline
\end{tabular}

function is used to describe the influence of each secondary influencing factor. The entropy weight method is used to determine the weights of the primary and secondary influencing factors.

5.1. Standardized Membership Functions. Normal membership function: the commonly used membership functions in geotechnical engineering area are normal-type functions, triangular fuzzy functions, trapezoidal functions, and ridgetype functions [28]. The parameter membership function that in geotechnical engineering should adopt an exponential normal distribution function was suggested [29]. Therefore, the membership function [30] of the structural influencing factor $u_{\mathrm{ij}}$ on the evaluation index is as follows:

$$
f_{k}\left(u_{i j}\right)=\exp \left[-\left(\frac{u_{i j}-a_{i j}^{(k)}}{c_{i j}^{k}}\right)^{2}\right],
$$

where $k$ is the evaluation index of $u_{i j}$ and $a_{i j}^{(k)}$ and $c_{i j}^{(k)}$ are constants, satisfying $a_{i j}^{(k)}>0$ and $c_{i j}^{(k)}>0$.

Standardization of membership functions: to give a standardized membership function, the classification interval of the secondary influencing factor is linearly converted into a classification standard interval with the same size as the evaluation index. According to the level $k$ to which $u_{i j}$ belongs, the positive and negative attribute factors have been normalized separately. After standardized treatment of influencing factors, the classification standards of each factor are consistent with the classification ranges of the postconstruction settlement classification standards in Table $1 . a_{i j}^{(k)}$ and $c_{i j}^{(k)}$ can be calculated using the upper and lower boundaries of the classification intervals of each factor classification standard. For the evaluation index level $v_{1} \sim v_{4}$, the normal distribution membership function in the form of the normalized index is

$$
\begin{aligned}
& \left\{\begin{array}{l}
1 \\
y_{i j}<0.125
\end{array}\right. \\
& r_{i j}^{(1)}=\left\{\begin{array}{ll}
\exp \left[-\left(\frac{y_{i j}-0.125}{0.15014}\right)^{2}\right] & 0.125 \leq y_{i j}<0.25 \\
1-\exp \left[-\left(\frac{y_{i j}-0.375}{0.15014}\right)^{2}\right] & 0.25 \leq y_{i j}<0.375 \\
0 & 0.375 \leq y_{i j}<1
\end{array},\right. \\
& r_{i j}^{(2)}= \begin{cases}0 & y_{i j}<0.125 \vee y_{i j} \geq 0.625 \\
1-\exp \left[-\left(\frac{y_{i j}-0.125}{0.15014}\right)^{2}\right] & 0.125 \leq y_{i j}<0.25 \\
\exp \left[-\left(\frac{y_{i j}-0.375}{0.15014}\right)^{2}\right] & 0.25 \leq y_{i j}<0.50 \\
1-\exp \left[-\left(\frac{y_{i j}-0.625}{0.15014}\right)^{2}\right] & 0.50 \leq y_{i j}<0.625\end{cases} \\
& r_{i j}^{(3)}=\left\{\begin{array}{ll}
0 & y_{i j}<0.375 \vee y_{i j} \geq 0.875 \\
1-\exp \left[-\left(\frac{y_{i j}-0.375}{0.15014}\right)^{2}\right] & 0.375 \leq y_{i j}<0.50 \\
\exp \left[-\left(\frac{y_{i j}-0.625}{0.15014}\right)^{2}\right] & 0.50 \leq y_{i j}<0.75 \\
1-\exp \left[-\left(\frac{y_{i j}-0.875}{0.15014}\right)^{2}\right] & 0.75 \leq y_{i j}<0.875
\end{array},\right.
\end{aligned}
$$




$$
r_{i j}^{(4)}=\left\{\begin{array}{ll}
0 & y_{i j}<0.625 \\
1-\exp \left[-\left(\frac{y_{i j}-0.625}{0.15014}\right)^{2}\right] & 0.625 \leq y_{i j}<0.75 \\
\exp \left[-\left(\frac{y_{i j}-0.875}{0.15014}\right)^{2}\right] & 0.75 \leq y_{i j}<0.875 \\
1 & y_{i j} \geq 0.875
\end{array},\right.
$$

where $y_{i j}$ is the normalized value of the influencing factor; $r_{i j}^{(k)}$ is the standard membership value of each influencing factor, and $k=1,2,3$, and 4 . The membership of each secondary influencing factor can be obtained using formulas (6) to (9). After obtaining the membership value of each secondary influencing factor, a matrix $R_{i}$ can be constructed:

$$
\mathbf{R}_{i}=\left[\begin{array}{cccc}
r_{i 1}^{(1)} & r_{i 1}^{(2)} & r_{i 1}^{(3)} & r_{i 1}^{(4)} \\
r_{i 2}^{(1)} & r_{i 2}^{(2)} & r_{i 2}^{(3)} & r_{i 2}^{(4)} \\
\vdots & \vdots & \vdots & \vdots \\
r_{i n_{i}}^{(1)} & r_{i n_{i}}^{(2)} & r_{i n_{i}}^{(3)} & r_{i n_{i}}^{(4)}
\end{array}\right] .
$$

5.2. Weights of Influencing Factors. In the fuzzy comprehensive evaluation of multiple influencing factors, the weight is a measure of the influence of each influencing factor on the evaluation index. The method of determining the weight can generally be divided into subjective empowerment and objective weighting methods. Common subjective empowerment methods have Delphi method, analytic hierarchy process, and statistical method. Common objective weighting methods include entropy weight method, principal component analysis method, and mean square error method. As the subjective empowerment method relies on human factors, such as expert experience which may cause bias on the evaluation results, the entropy weight method in the objective weighting method is used to determine the weight of the influencing factors.

Entropy is a physical quantity that reflects the randomness and disorder of subjects. The weight of each influencing factor can be constructed based on the entropy of each influencing factor [31]. The steps for determining the weights of influencing factors by the entropy weight method are provided as follows [32]:

(1) Collect the influencing factor samples from $T$ projects. The projects are ordered and $t$ is the index of the project.

(2) Calculate the normalization value $y_{i j, t}$ of the secondary influencing factors.

(3) Calculate the ratio $p_{i j, t}$ by

$$
p_{i j, t}=\frac{y_{i j, t}}{\sum_{t=1}^{T} y_{i j, t}} .
$$

(4) Calculate the entropy $E_{i j}$ of the secondary influencing factor $u_{i j}$ with

$$
E_{i j}=-\xi \sum_{t=1}^{T} p_{i j, t} \ln \left(p_{i j, t}\right)
$$

where $\xi=1 / \ln (T)$ is a constant related to the number of samples. $p_{i j, t}$ has three requirements:

$$
\begin{aligned}
p_{i j, t} & \in[0,1], \\
\sum_{t=1}^{T} p_{i j, t} & =1, \\
p_{i j, t} \ln \left(p_{i j, t}\right) & =\left.0\right|_{p_{i j, t}=0 .}
\end{aligned}
$$

The larger $E_{i j}$ is, the smaller the information of $U_{i}$ contained in $u_{i j}$ is and vice versa.

(5) Calculate the difference coefficient $d_{i j}$ of each secondary influencing factor $E_{i j}$ by

$$
d_{i j}=1-E_{i j} \text {. }
$$

And then calculate the weight $w_{i j}$ of $u_{i j}$ w.r.t. $U_{i}$. The expression of $w_{i j}$ is

$w_{i j}=\frac{d_{i j}}{\sum_{j=1}^{n_{i}} d_{i j}}=\frac{1-E_{i j}}{\sum_{j=1}^{n_{i}}\left(1-E_{i j}\right)}=\frac{1-E_{i j}}{n_{i}-\sum_{j=1}^{n_{i}} E_{i j}}$.

According to formula (15), a weight vector for the secondary influencing factors can be obtained, we have

$$
W_{i}=\left[w_{i 1}, w_{i 2}, \ldots, w_{i n_{i}}\right],
$$

where all weight factors satisfy $\sum_{j=1}^{n_{i}} w_{i j}=1$ naturally.

(6) Use formula (16) to calculate the normalized value $Y_{i, t}$ of the primary influencing factor $U_{i, t}$ for project $t$, and we have

$$
Y_{i, t}=\sum_{j=1}^{n_{i}} w_{i j} y_{i j, t} .
$$

(7) Use the entropy weight method similar to the process from Steps 2 to 5, the weight of the primary influencing factors can be calculated. According to formula (11), the ratio $P_{i, t}$ and entropy $E_{i}$ of the primary influencing factor $U_{i, t}$ are computed by

$$
\begin{aligned}
P_{i, t} & =\frac{Y_{i, t}}{\sum_{t=1}^{T} Y_{i, t}}, \\
E_{i} & =-\xi \sum_{t=1}^{T} P_{i, t} \ln \left(P_{i, t}\right),
\end{aligned}
$$

when $P_{i, t}=0, P_{i, t} \ln \left(P_{i, t}\right)=0$. The difference coefficient that defines for the primary influencing factor $U_{i}$ is 


$$
D_{i}=1-E_{i} .
$$

The weight of the primary influencing factors on the evaluation indicators is

$$
\begin{aligned}
w_{i} & =\frac{D_{i}}{\sum_{i=1}^{4} D_{i j}} \\
& =\frac{1-E_{i}}{\sum_{i=1}^{4}\left(1-E_{i}\right)} \\
& =\frac{1-E_{i}}{4-\sum_{i=1}^{4} E_{i}} .
\end{aligned}
$$

A weight vector of the primary influencing factors can be obtained:

$$
W=\left[w_{1}, w_{2}, w_{3}, w_{4}\right],
$$

where all weight factors satisfy $\sum_{i=1}^{4} w_{i}=1$.

\section{Postconstruction Settlement Assessment Method for Two-Level Fuzzy Comprehensive Evaluation}

After introducing the evaluation index, the influencing factor grading standard, the standardized membership function, the weight of the influencing factors, and a twolevel fuzzy comprehensive evaluation method of the postconstruction settlement of the CFG pile composite subgrade are proposed in this section.

\subsection{Evaluation Procedure.}

(1) According to the postconstruction settlement requirements of the CFG pile composite subgrade in different road sections and the factors affecting the postconstruction settlement, the evaluation index evaluation set $V$, the primary influencing factor set $U$, and the secondary influencing factor set $U_{i}$ are determined. The secondary influencing factors are the inputs of this model.

(2) Derive the relationship matrix $R_{i}$ for each primary influencing factors based on formula (10).

(3) Based on formula (16), determine the comprehensive evaluation vector $B_{i}$ for the primary influencing factor $U_{i}$ using

$$
\begin{aligned}
B_{i} & =W_{i} \circ R_{i} \\
& =\left[b_{i}^{(1)}, b_{i}^{(2)}, b_{i}^{(3)}, b_{i}^{(4)}\right],
\end{aligned}
$$

where "o" is the sign of the composition operator; this paper takes the composition operator as the addition and multiplication operator $M(\mathrm{~g}+)$, namely,

$$
b_{i}^{(k)}=\sum_{j=1}^{n_{i}} w_{i j} r_{i j}^{(k)} .
$$

(4) Construct the relationship matrix $R$ for the primary influencing factors:

$$
\begin{aligned}
\mathbf{R} & =\left[\begin{array}{l}
B_{1} \\
B_{2} \\
B_{3} \\
B_{4}
\end{array}\right] \\
& =\left[\begin{array}{llll}
b_{1}^{(1)} & b_{1}^{(2)} & b_{1}^{(3)} & b_{1}^{(4)} \\
b_{2}^{(1)} & b_{2}^{(2)} & b_{2}^{(3)} & b_{2}^{(4)} \\
b_{3}^{(1)} & b_{3}^{(2)} & b_{3}^{(3)} & b_{3}^{(4)} \\
b_{4}^{(1)} & b_{4}^{(2)} & b_{4}^{(3)} & b_{4}^{(4)}
\end{array}\right] .
\end{aligned}
$$

(5) Calculate the evaluation vector $B$ for the evaluation index by using

$$
B=W \circ \mathbf{R}=\left[b_{1}, b_{2}, b_{3}, b_{4}\right],
$$

where

$$
b_{k}=\sum_{i=1}^{4} w_{i} b_{i}^{(k)} .
$$

(6) Determine the evaluation results of the postconstruction settlement based on the value of the element in the evaluation vector $B$.

6.2. Weights of Factors Affecting Postconstruction Settlement of CFG Pile Composite Subgrade. Taking CFG pile composite subgrade in Guangdong Province as an example, the calculation process and analysis method of the index weight of each layer are described. With the support from the Guangdong Province Transportation Engineering Quality Supervision Station, the authors have collected the design and construction data from 71 different CFG pile composite subgrade road sections in Guangdong Province area. All the CFG pile composite subgrade road sections have operated for 2 to 5 years. Based on the entropy weight method mentioned in the previous section, the weights of the secondary influencing factors are calculated and given in Tables 5 and 6.

According to the secondary weight factor values shown in Tables 5 and 6, the weights of the internal friction angle $(2.5 \%)$ of the subgrade soil and the filling rate $(9.3 \%)$ are relatively small, and they have little effect on their corresponding primary influencing factors. The weights of all other secondary influencing factors exceed $20 \%$ and smaller than $50 \%$, which is satisfied with our claim that the postconstruction settlement of CFG pile composite subgrade depends on many factors. The weights of all the secondary influencing factors are in consistent with the sensitivity analysis results discussed in the previous section.

Similarly, the weights of the primary influencing factors can be computed. The results are shown in Table 7.

The data in Table 7 show that the weights of the influencing factors of cushion, pile, construction, and geology are reduced in descending order, meaning their 
TABLE 5: Weights of geological and pile secondary influencing factors.

\begin{tabular}{lcccccccc}
\hline & \multicolumn{3}{c}{ Geological influencing } & \multicolumn{4}{c}{ Pile influencing factor } \\
Index & \multicolumn{3}{c}{ factor $U_{1}$} & \multicolumn{5}{c}{$U_{2}$} \\
& $u_{11}$ & $u_{12}$ & $u_{13}$ & $u_{14}$ & $u_{21}$ & $u_{22}$ & $u_{23}$ & $u_{24}$ \\
\hline Weights (\%) & 39.1 & 35.9 & 22.5 & 2.5 & 27.4 & 24.3 & 26.9 & 21.4 \\
\hline
\end{tabular}

TABLE 6: Weights of cushion and construction secondary influencing factors.

\begin{tabular}{lccccccc}
\hline & \multicolumn{3}{c}{ Cushion } & \multicolumn{4}{c}{ Construction influencing } \\
Index & $\begin{array}{c}\text { influencing factor } \\
U_{3}\end{array}$ & & \multicolumn{4}{c}{ factor $U_{4}$} \\
& $u_{31}$ & $u_{32}$ & $u_{33}$ & $u_{41}$ & $u_{42}$ & $u_{43}$ & $u_{44}$ \\
\hline Weights (\%) & 41.1 & 21.7 & 37.2 & 22.3 & 9.3 & 37.4 & 31.0 \\
\hline
\end{tabular}

TABLE 7: Weights of primary factor index.

\begin{tabular}{lc}
\hline Index & Weights (\%) \\
\hline Geological influencing factor $U_{1}$ & 15.7 \\
Pile influencing factor $U_{2}$ & 29.4 \\
Cushion influencing factor $U_{3}$ & 34.8 \\
Construction influencing factor $U_{4}$ & 20.1 \\
\hline
\end{tabular}

influences on the postconstruction settlement are reduced in turn. For composite subgrade, the cushion plays a role in adjusting the stress ratio of the pile and soil and determines the structural form of the bearing system. The pile is the main bearing part for undertaking the weight of the composite subgrade. Hence, the weight of the geological influencing factor is the smallest (15.7\%) among all the primary influencing factors. However, none of the primary influencing factors can be neglected. The calculated weights of the primary influencing factors also indicate that the proposed entropy weight method can be used for analysing the relationships between the primary influencing factors and the postconstruction settlements.

\subsection{Example Analysis}

6.3.1. Model Inputs. A bridge transition section in Guangdong Province has been selected to validate the proposed evaluation method. The target bridge transition section has CFG pile composite subgrade. The geological conditions and construction information are concluded as follows. The compressed soil thickness $u_{11}$ is $22.6 \mathrm{~m}$, the averaged compression modulus $u_{12}$ is $6450 \mathrm{kPa}$, the averaged cohesion $u_{13}$ is $9.5 \mathrm{kPa}$, and the internal friction angle $u_{14}$ is $6.7^{\circ}$. The pile diameter $u_{23}$ is $0.4 \mathrm{~m}$, the pile length $u_{22}$ is $25 \mathrm{~m}$, the pile spacing $u_{24}$ is $2.2 \mathrm{~m}$, and the pile modulus $u_{21}$ is $8.0 \mathrm{GPa}$. The piles have a plum-type arrangement. The gravel cushion thickness $u_{31}$ is $30 \mathrm{~cm}$, the cushion modulus $u_{32}$ is $100 \mathrm{MPa}$, and the cushion internal friction angle $u_{33}$ is $35^{\circ}$. The filling height $u_{41}$ is $5.3 \mathrm{~m}$, and the filling rate $u_{42}$ is $80 \mathrm{~mm} / \mathrm{d}$. Due to the tight schedule, the preloading process has not been applied in this road section. In this case, the preloading height $u_{43}$ and preloading time $u_{44}$ are 0 . The index value and normalized value of secondary influencing factors are shown in Tables 8 and 9.

6.3.2. Postconstruction Settlement Prediction. Based on the information of the target road section, the relationship matrix $R_{i}$ of each secondary influencing factors can be obtained. Following the process mentioned in the previous section, the relationship matrix $R$ can be computed and we have

$$
\begin{aligned}
\mathbf{R} & =\left[\begin{array}{c}
B_{1} \\
B_{2} \\
\vdots \\
B_{s}
\end{array}\right] \\
& =\left[\begin{array}{l}
W_{1} R_{1} \\
W_{2} R_{2} \\
W_{3} R_{3} \\
W_{4} R_{4}
\end{array}\right] \\
& =\left[\begin{array}{cccc}
0.533 & 0.451 & 0.015 & 0 \\
0.280 & 0.362 & 0.358 & 0 \\
0.242 & 0.728 & 0.030 & 0 \\
0.279 & 0.037 & 0 & 0.684
\end{array}\right] .
\end{aligned}
$$

According to the principle of the maximum membership, it can be seen from the matrix $R$ that the level of geological influencing factors is excellent, the level of pileinfluencing factors and cushion-influencing factors are good, and the level of construction-influencing factors is bad. The analysis conclusion is consistent with the reality that no preloading was performed to the target road section.

According to equation (25), the comprehensive evaluation vector for the postconstruction settlement of CFG pile composite subgrade can be obtained as

$$
B=W \circ \mathbf{R}=\left[\begin{array}{llll}
0.222 & 0.275 & 0.262 & 0.192
\end{array}\right] .
$$

According to the principle of maximum membership, the evaluation result of the postconstruction settlement is good. Namely, the range of the postconstruction settlement is $[100 \mathrm{~mm}, 200 \mathrm{~mm})$.

The construction of the target road section was completed and opened to traffic in July 2015. The observation frequency of the postconstruction settlement is shown in Table 10 and the collected postconstruction settlement data are shown in Figure 5.

According to the field observation data, the current settlement is $88.7 \mathrm{~mm}$. Using the hyperbolic method, the final postconstruction settlement of the CFG pile composite subgrade after 15 years operation is $164.23 \mathrm{~mm}$, which satisfies the calculation and evaluation results. Since the road section is a transitional section at the bridgehead, the allowable value of its postconstruction settlement should be less than $100 \mathrm{~mm}$. Hence, certain remedial measures, such as 
TABLE 8: Index value and normalized value of geological and pile secondary influencing factors.

\begin{tabular}{lccccccc}
\hline \multirow{2}{*}{ Index } & \multicolumn{3}{c}{ Geological influencing factors $U_{1}$} & \multicolumn{3}{c}{ Pile influencing factors $U_{2}$} \\
& $u_{11}(\mathrm{~m})$ & $u_{12}(\mathrm{MPa})$ & $u_{13}(\mathrm{kPa})$ & $u_{21}(\mathrm{MPa})$ & $u_{22}(\mathrm{~m})$ & $u_{23}(\mathrm{~m})$ & $u_{24}(\mathrm{~m})$ \\
\hline Index value $u_{i j}$ & 22.6 & 6.45 & 9.5 & $8.0 \times 10^{3}$ & 25.0 & 0.4 \\
Normalized value $y_{i j}$ & 0.405 & 0.198 & 0.124 & 0.599 & 0.078 & 0.472 & 0.310 \\
\hline
\end{tabular}

TABLE 9: Index value and normalized value of cushion and construction secondary influencing factors.

\begin{tabular}{lcccccc}
\hline \multirow{2}{*}{ Index } & \multicolumn{3}{c}{ Cushion influencing factors $U_{3}$} & \multicolumn{3}{c}{ Construction influencing factors $U_{4}$} \\
& $u_{31}(\mathrm{~m})$ & $u_{32}(\mathrm{MPa})$ & $u_{33}\left({ }^{\circ}\right)$ & $u_{41}(\mathrm{~m})$ & $u_{42}(\mathrm{~mm} / \mathrm{d})$ & $u_{43}(\mathrm{~m})$ \\
\hline Index value $u_{i j}$ & 0.3 & 100.0 & 35.0 & 5.3 & 80.0 & $u_{44}(\mathrm{~d})$ \\
Normalized value $y_{i j}$ & 0.346 & 0.433 & 0.231 & 0.101 & 0.232 & 0.0 \\
\hline
\end{tabular}

TABLE 10: Monitoring frequency of postconstruction settlement.

\begin{tabular}{lccc}
\hline Period & $0 \sim 6$ months & $7 \sim 18$ months & $18 \sim 30$ months \\
\hline Frequency & 2 times/month & 1 time/month & 1 time $/ 2$ months \\
\hline
\end{tabular}

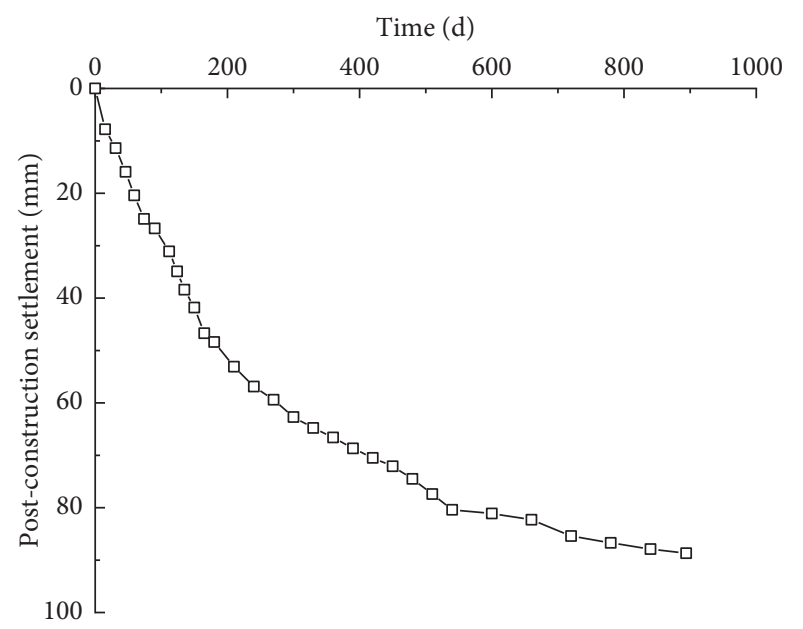

FIgURe 5: Postconstruction settlement monitoring data.

grouting, are necessary for this road section so as to meet the regulations.

\section{Conclusion}

In this paper, a two-level fuzzy comprehensive evaluation method is proposed for evaluating the postconstruction settlement of the CFG pile composite subgrade. Four primary influencing factors and 15 secondary factors are selected as the indexes to build the two-level evaluation system.

The entropy weight method and normal membership function with the normalization process are used to describe the fuzzy relationship between the evaluation results and the influencing factors.

A real bridgehead road section example in Guangdong Province has been selected to validate the proposed fuzzy comprehensive evaluation method. The evaluation results of the proposed method are in consistent with the field test results. Hence, the proposed fuzzy comprehensive evaluation method can be used to evaluate the construction quality of the CFG pile composite subgrade.

The FCE method requires a large amount of data and is complicated to calculate. Moreover, the samples used in this paper to calculate the weight of influencing factors are mainly from Guangdong Province, China, which has certain limitations. Moving forward, efforts will be made to explore how to reduce the subjectivity in the determination of evaluation factors and weights and therefore to construct a more rational and adaptive FCE method.

\section{Data Availability}

The data used to support the findings of this study are presented in the tables and figures.

\section{Disclosure}

This work is an original one conducted at Xuzhou University of Technology. The work described has not been submitted elsewhere for publication, in whole or in part.

\section{Conflicts of Interest}

The authors declare that there are no conflicts of interest regarding the publication of this paper.

\section{Authors' Contributions}

All the authors have contributed to and approved this paper.

\section{Acknowledgments}

This work was supported by the National Science Foundation for Young Scientists of China (grant no. 51904270).

\section{References}

[1] X. Liu, K. Sheng, Z. Li, L. Gan, H. Shan, and B. Hong, "Experimental research on foamed mixture lightweight soil mixed with fly-ash and quicklime as backfill material behind abutments of expressway bridge," Advances in Materials Science and Engineering, vol. 2017, Article ID 5767103, 11 pages, 2017.

[2] B. Hong, H. Shan, X. Liu, F. Xu, and K. Sheng, "A novel incipient evaluation method for postconstruction settlement 
by using a statistic approach with time-extended loading test," Mathematical Problems in Engineering, vol. 2019, Article ID 8687178, 12 pages, 2019.

[3] H. Eid and A. Shehada, "Estimating the elastic settlement of piled foundations on rock," International Journal of Geomechanics, vol. 15, no. 3, Article ID 4014059, 2015.

[4] M. Liu, D. Huang, Y. Song, and D. Cen, "Numerical and theoretical study on the settlement of capped piles composite foundation under embankment," Advances in Civil Engineering, vol. 2020, Article ID 3978780, 11 pages, 2020.

[5] H. Wang, H. She, J. Xu, and L. Liang, "A three-point hyperbolic combination model for the settlement prediction of subgrade filled with construction and demolition waste," Materials, vol. 13, no. 8, Article ID 1959, 2020.

[6] F. Yu, S. Li, Z. Dai, J. Li, and S. Chen, "Stability control of staged filling construction on soft subsoil using hyperbolic settlement prediction method: a case study of a tidal flat in China," Advances in Civil Engineering, vol. 2020, Article ID 8899843, 11 pages, 2020.

[7] M. Omar, K. Hamad, M. Al Suwaidi, and A. Shanableh, "Developing artificial neural network models to predict allowable bearing capacity and elastic settlement of shallow foundation in Sharjah, United Arab Emirates," Arabian Journal of Geosciences, vol. 11, no. 16, p. 464, 2018.

[8] Z. Wang, W. Cheng, Y. Wang, and J. Du, "Simple method to predict settlement of composite foundation under embankment," International Journal of Geomechanics, vol. 18, no. 12, Article ID 4018158, 2018.

[9] F.-Y. Meng, R.-P. Chen, and X. Kang, "Effects of tunnelinginduced soil disturbance on the post-construction settlement in structured soft soils," Tunnelling and Underground Space Technology, vol. 80, pp. 53-63, 2018.

[10] M. Kermani, J.-M. Konrad, and M. Smith, "An empirical method for predicting post-construction settlement of concrete face rockfill dams," Canadian Geotechnical Journal, vol. 54, no. 6, pp. 755-767, 2017.

[11] Y. Cai, Y. Chen, Z. Cao, and C. Ren, “A combined method to predict the long-term settlements of roads on soft soil under cyclic traffic loadings," Acta Geotechnica, vol. 13, no. 5, pp. 1215-1226, 2018.

[12] M. Mohammed, A. Sharafati, N. Al-Ansari, and Z. Yaseen, "Shallow foundation settlement quantification: application of hybridized adaptive neuro-fuzzy inference system model," Advances in Civil Engineering, vol. 2020, Article ID 7381617, 14 pages, 2020.

[13] L. Tang, Q. Zhang, and H. Liao, "Advance in post-construction settlement of soft subgrade soil," Chinese Journal of Rock Mechanics and Engineering, vol. 25, no. S2, pp. 3449-3455, 2006.

[14] M. Ding, "Numerical simulation on the post-construction settlement of CFG pile-slab composite foundation in high-speed railway," China Railway Science, vol. 29, no. 3, pp. 1-6, 2008.

[15] F. Zhang, Y. Liu, Z. Xu, and Z. Li, "Factors influencing subgrade post-construction settlement of CFG pile composite foundation in Wuhan-Guangzhou high-speed railway," Journal of Southwest Jiaotong University, vol. 50, no. 5, pp. 783-788, 2015.

[16] X. Li, X. Liu, C. Z. Li, Z. Hu, G. Q. Shen, and Z. Huang, "Foundation pit displacement monitoring and prediction using least squares support vector machines based on multipoint measurement," Structural Health Monitoring, vol. 18, no. 3, pp. 715-724, 2019.

[17] S. Golnaraghi, Z. Zangenehmadar, O. Moselhi, and S. Alkass, "Application of artificial neural network (s) in predicting formwork labour productivity," Advances in Civil Engineering, vol. 2019, Article ID 5972620, 11 pages, 2019.
[18] D. Zhang, S. Yang, Z. Wang, C. Yang, and Y. Chen, "Assessment of ecological environment impact in highway construction activities with improved group AHP-FCE approach in China," Environmental Monitoring and Assessment, vol. 192, no. 7, p. 451, Article ID 451, 2020.

[19] Y. Li, Z. Gao, and Y. Han, "The determination of weight value and the choice of composite operators in fuzzy comprehensive evaluation," Computer Engineering and Applications, vol. 42, no. 23, pp. 38-42+197, 2006.

[20] Q. Xu, J. Zhao, X. Ai, W. Huang, and G. Wang, "Optimum selection of tool materials for machining of high-strength steels based on fuzzy comprehensive evaluation method," Proceedings of the Institution of Mechanical Engineers-Part B: Journal of Engineering Manufacture, vol. 233, no. 1, pp. 145-153, 2019.

[21] C.-F. Huang, Q. Li, S.-C. Wu, J.-Y. Li, and X.-L. Xu, “Application of the richards model for settlement prediction based on a bidirectional difference-weighted least-squares method," Arabian Journal for Science and Engineering, vol. 43, no. 10, pp. 5057-5065, 2017.

[22] D. Armaghani, P. Asteris, S. Fatemi et al., "On the use of neuro-swarm system to forecast the pile settlement," Applied Sciences, vol. 10, no. 6, p. 1904, 2020.

[23] D. J. Armaghani, R. S. Faradonbeh, H. Rezaei, A. S. A. Rashid, and H. B. Amnieh, "Settlement prediction of the rocksocketed piles through a new technique based on gene expression programming," Neural Computing \& Applications, vol. 29, no. 11, pp. 1115-1125, 2018.

[24] M. Zhang and Y. Zhang, "Stability evaluation method for gateways in closely spaced coal seams and surrounding rock control technology," Arabian Journal for Science and Engineering, vol. 43, no. 10, pp. 5469-5485, 2018.

[25] J. Wang, P. Song, Z. Wang, B. Zhang, W. Liu, and J. Yu, “A combined model for regional eco-environmental quality evaluation based on particle swarm optimization-radial basis function network," Arabian Journal for Science and Engineering, vol. 41, no. 4, pp. 1483-1493, 2016.

[26] H. Liao, X. Yang, F. Xu, H. Xu, and J. Zhou, "A fuzzy comprehensive method for the risk assessment of a landslidedammed lake," Environmental Earth Sciences, vol. 77, no. 22, p. 750, 2018.

[27] Q. Yao, X. Yang, and H. Li, “A fuzzy AHP-based method for comprehensive blasting vibration comfort evaluation forecast," Advances in Civil Engineering, vol. 2020, Article ID 8919314, 11 pages, 2020.

[28] Y. Su, M. He, and X. Sun, "Equivalent characteristic of membership function type in rock mass fuzzy classification," Journal of University of Science and Technology Beijing, vol. 29, no. 7, pp. 670-675, 2007.

[29] L. Sun, H. Zhang, and N. Zhou, "Application of random-fuzzy statistical method to statistics of geotechnical parameters," Rock and Soil Mechanics, vol. 33, no. 3, pp. 821-826, 2012.

[30] P. Chen, H. Yu, and H. Shi, "Prediction model for rockburst based on weighted back analysis and standardized fuzzy comprehensive evaluation," Chinese Journal of Rock Mechanics and Engineering, vol. 33, no. 10, pp. 2154-2160, 2014.

[31] K.-P. Zhou, Y. Lin, H.-W. Deng, J.-L. Li, and C.-J. Liu, "Prediction of rock burst classification using cloud model with entropy weight," Transactions of Nonferrous Metals Society of China, vol. 26, no. 7, pp. 1995-2002, 2016.

[32] M. Qi, G. Fu, Y. Jing, and Y. Ma, "A comprehensive evaluation method of power plant units based on information entropy and principal component analysis," Proceedings of the CSEE, vol. 33, no. 2, pp. 58-64+S9, 2013. 